\title{
Optimal Timing of Venoarterial-Extracorporeal Membrane Oxygenation in Acute Myocardial Infarction Patients Suffering From Refractory Cardiogenic Shock
}

\author{
Ki Hong Choi, MD; Jeong Hoon Yang, MD; David Hong, MD; Taek Kyu Park, MD; \\ Joo Myung Lee, MD; Young Bin Song, MD; Joo-Yong Hahn, MD; Seung-Hyuk Choi, MD; \\ Jin-Ho Choi, MD; Su Ryeun Chung, MD; Yang Hyun Cho, MD, PhD; Dong Seop Jeong, MD; \\ Kiick Sung, MD; Wook Sung Kim, MD; Young Tak Lee, MD, PhD; Hyeon-Cheol Gwon, MD
}

\begin{abstract}
Background: Although there is an increase in the use of mechanical circulatory support devices to rescue patients with acute myocardial infarction (AMI) complicated by refractory cardiogenic shock (CS), the optimal timing of the application remains controversial. Therefore, this study aimed to compare the clinical outcomes between venoarterial-extracorporeal membrane oxygenation (VA-ECMO) insertion before and after coronary revascularization in AMI patients with refractory CS.

Methods and Results: A total of 253 patients with AMI who underwent revascularization therapy with VA-ECMO were included. The study population was stratified into extracorporeal cardiopulmonary resuscitation (E-CPR) before revascularization $(\mathrm{N}=106$, reference cohort) and refractory CS without E-CPR before revascularization ( $n=147$, comparison cohort). Patients with refractory CS but without E-CPR before revascularization were further divided into VA-ECMO before revascularization ( $N=50)$ and VA-ECMO after revascularization $(n=97)$. The primary endpoint was a composite of in-hospital mortality, left ventricular assist device implantation, and heart transplantation. The primary endpoint occurred in 60 patients (40.8\%) of the comparison cohort and 51 patients (48.1\%) of the reference cohort. Among the comparison cohort, the primary endpoint was significantly lower in VA-ECMO before revascularization than in VA-ECMO after revascularization ( $32.0 \%$ vs. $49.5 \%$, OR $0.480,95 \% \mathrm{Cl} 0.235-0.982, \mathrm{P}=0.045)$. A similar trend was observed after a 1-year follow up.
\end{abstract}

Conclusions: Early initiation of VA-ECMO before revascularization therapy might improve clinical outcomes in patients with AMI complicated by refractory CS.

Key Words: Acute myocardial infarction; Cardiogenic shock; Extracorporeal membrane oxygenation; Prognosis; Timing

D espite advances in medical therapy and devices to treat acute myocardial infarction (AMI), AMI complicated by cardiogenic shock (CS) is still a leading cause of death, with a mortality rate of over $50 \%$, even in the era of primary percutaneous coronary intervention (PCI). ${ }^{1-3}$ In this regard, short-term mechanical circulatory support (MCS) devices including intra-aortic balloon pump, venoarterial-extracorporeal membrane oxygenation (VA-ECMO), and percutaneous left ventricular assist device (LVAD), have been developed and widely used to rescue patients with refractory CS in real-world practice. ${ }^{4,5}$ Although several observational studies have demonstrated the benefits of MCS for patients with CS, ${ }^{6-11}$

\begin{abstract}
Editorial p1461
there are no large-scale, randomized trials on the efficacy and safety of temporary MCS; therefore, the current guidelines suggest that short-term MCS may be considered for carefully selected patients with AMI and refractory CS as a class IIb recommendation. ${ }^{12,13}$

In practice, the initiation of VA-ECMO should be carefully considered because ECMO-related complications still remain high, even though VA-ECMO can provide superior hemodynamic support compared to pharmacotherapy. In particular, pre-emptive insertion of VA-ECMO for AMI
\end{abstract}

Received March 25, 2020; revised manuscript received April 22, 2020; accepted May 25, 2020; J-STAGE Advance Publication released online July 17, 2020 Time for primary review: 20 days

Division of Cardiology, Department of Medicine, Heart Vascular Stroke Institute (K.H.C., J.H.Y., D.H., T.K.P., J.M.L., Y.B.S., J.-Y.H., S.-H.C., J.-H.C., H.-C.G.), Department of Critical Care Medicine (J.H.Y.), Department of Emergency Medicine (J.-H.C.), and Department of Thoracic and Cardiovascular Surgery (S.R.C., Y.H.C., D.S.J., K.S., W.S.K., Y.T.L.), Samsung Medical Center, Sungkyunkwan University School of Medicine, Seoul, Republic of Korea

Mailing address: Jeong Hoon Yang, MD, PhD, Division of Cardiology, Department of Critical Care Medicine and Medicine, Samsung Medical Center, Sungkyunkwan University School of Medicine, Seoul 06351, Republic of Korea. E-mail: jhysmc@gmail.com

All rights are reserved to the Japanese Circulation Society. For permissions, please e-mail: cj@j-circ.or.jp

ISSN-1346-9843 


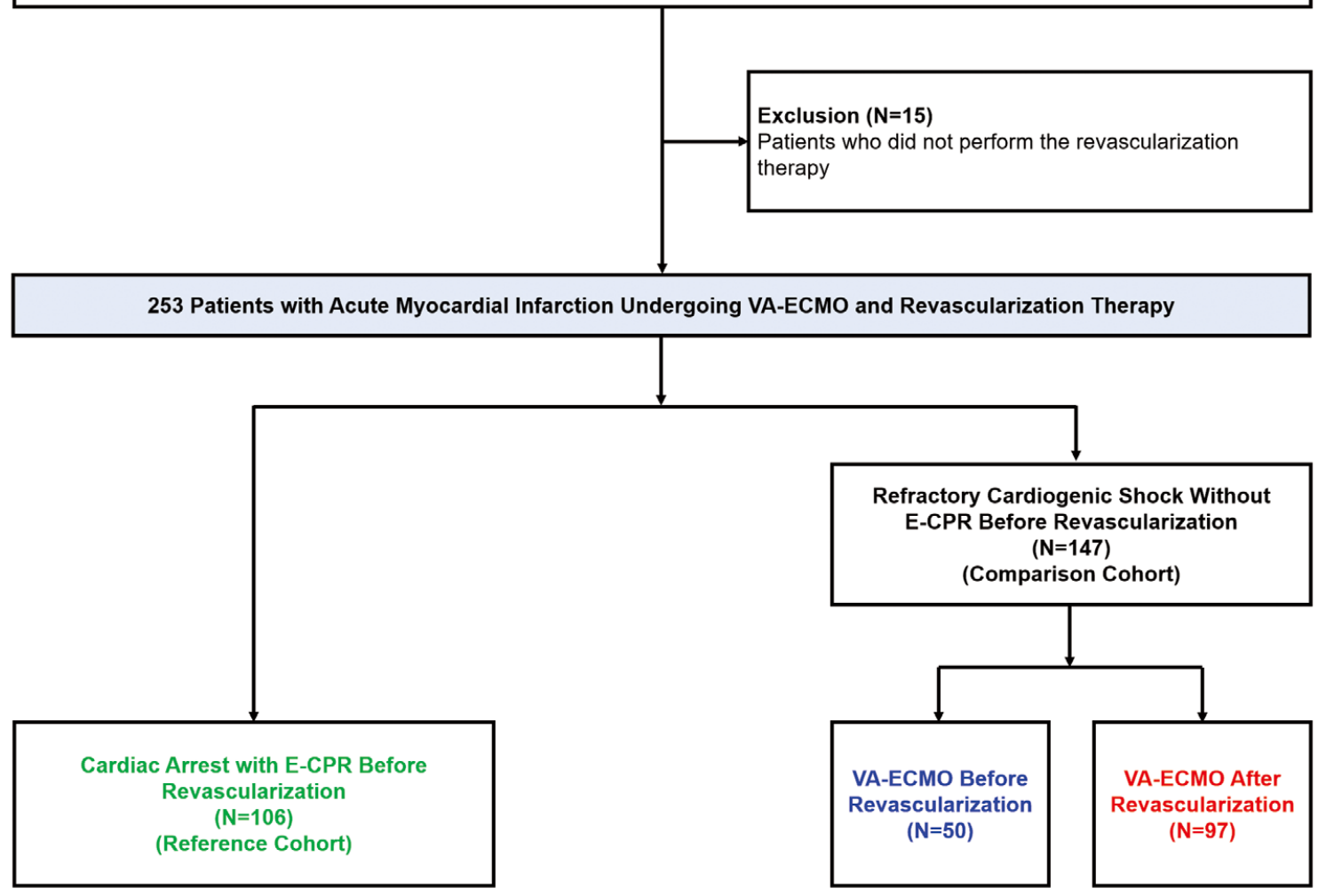

Figure 1. Study flowchart. E-CPR, extracorporeal cardiopulmonary resuscitation; VA-ECMO, venoarterial-extracorporeal membrane oxygenation.

patients complicated by CS without cardiac arrest might be controversial because insertion before revascularization could delay door-to-balloon (D2B) time and increase oxygen demand for the infarcted myocardium by increased afterload. Therefore, we sought to compare the clinical outcomes between VA-ECMO insertion before and after coronary artery revascularization in patients with AMI complicated by refractory CS without cardiac arrest prior to revascularization, to identify the optimal timing for the application of VA-ECMO.

\section{Methods}

\section{Study Population}

This was a retrospective, single center, observational study. Between May 2004 and December 2018, a total of 268 patients with AMI complicated by CS who underwent VAECMO were consecutively recruited from a prospective institutional VA-ECMO registry at Samsung Medical Center, Seoul, Korea. AMI was defined as an elevation of creatine kinase-myocardial band or troponin level greater than the upper limit of normal with concomitant ischemic symptoms or electrocardiography findings indicative of ischemia. CS was defined if the following 2 conditions were satisfied: (1) the requirement of inotrope or vasopressor support to achieve a systolic blood pressure $>90 \mathrm{mmHg}$; and (2) serum lactate $\geq 2.0 \mathrm{mmol} / \mathrm{L}$ to reflect tissue hypoperfusion. Among the total population, 15 patients who could not receive revascularization treatment were excluded from the current analysis. Patients with pre-emptive VA-ECMO insertion before high-risk PCI were not included in this registry. For the purpose of the current analysis, enrolled patients were stratified into cardiac arrest with E-CPR before revascularization $(n=106$, reference cohort) and refractory CS without E-CPR before revascularization $(n=147$, comparison cohort) (Figure 1). The comparison cohort was further divided into VA-ECMO before revascularization $(n=50)$ and VA-ECMO after revascularization $(n=97)$. The institutional review board of the Samsung Medical Center approved this study (reference number: 2019-10-119) and waived the requirement for written informed consent due to the retrospective nature of the study. This investigation was performed according to the Declaration of Helsinki.

\section{Revascularization and VA-ECMO Management}

The revascularization procedure and best available medical therapy were performed and provided according to the relevant standard guidelines. ${ }^{\mathbf{1 2}, 14}$ Revascularization strategy, choice of stent, the use of glycoprotein IIb/IIIa inhibi- 
Table 1. Baseline Clinical and Laboratory Characteristics

\begin{tabular}{|c|c|c|c|c|}
\hline \multirow[b]{2}{*}{ Variables } & \multicolumn{3}{|c|}{ Refractory cardiogenic shock } & \multirow{2}{*}{$\begin{array}{c}\text { Reference cohort } \\
\begin{array}{c}\text { E-CPR before } \\
\text { revascularization } \\
(n=106)\end{array}\end{array}$} \\
\hline & $\begin{array}{c}\text { Before } \\
\text { revascularization } \\
(n=50)\end{array}$ & $\begin{array}{c}\text { After } \\
\text { revascularization } \\
(n=97)\end{array}$ & P value* & \\
\hline \multicolumn{5}{|l|}{ Demographics } \\
\hline Age (years) & $66.9 \pm 11.0$ & $63.8 \pm 12.0$ & 0.129 & $62.8 \pm 11.6$ \\
\hline Male sex & $37(74.0)$ & $78(80.4)$ & 0.495 & $84(79.2)$ \\
\hline Body mass index $\left(\mathrm{kg} / \mathrm{m}^{2}\right)$ & $24.2 \pm 3.6$ & $24.1 \pm 3.4$ & 0.897 & $25.0 \pm 3.7$ \\
\hline Enrolled date & & & 0.405 & \\
\hline 2004-2007 & $6(12.0)$ & $13(13.4)$ & & $12(11.3)$ \\
\hline 2008-2011 & $10(20.0)$ & $31(32.0)$ & & $17(16.0)$ \\
\hline 2012-2015 & $12(24.0)$ & $21(21.6)$ & & $35(33.3)$ \\
\hline 2016-2018 & $22(44.0)$ & $32(33.0)$ & & $42(39.6)$ \\
\hline \multicolumn{5}{|l|}{ Cardiovascular risk factors } \\
\hline Hypertension & $27(54.0)$ & $51(52.6)$ & $>0.999$ & $56(52.8)$ \\
\hline Diabetes mellitus & $33(66.0)$ & $50(51.5)$ & 0.134 & $49(46.2)$ \\
\hline Chronic kidney disease & $4(8.0)$ & $13(13.4)$ & 0.485 & $10(9.4)$ \\
\hline Hyperlipidemia & $6(12.0)$ & $15(15.5)$ & 0.749 & $15(14.2)$ \\
\hline Current smoking & $13(26.0)$ & $42(43.3)$ & 0.061 & $24(23.1)$ \\
\hline Previous $\mathrm{PCl}$ & $15(30.0)$ & $29(29.9)$ & $>0.999$ & $33(31.1)$ \\
\hline Previous MI & $19(38.0)$ & $24(24.7)$ & 0.138 & $19(17.9)$ \\
\hline Peripheral vascular disease & $2(4.0)$ & $6(6.2)$ & 0.865 & $3(2.8)$ \\
\hline Previous CVA & $5(10.0)$ & $12(12.4)$ & 0.878 & $11(10.4)$ \\
\hline Malignancy & $2(4.0)$ & $5(5.2)$ & $>0.999$ & $10(9.4)$ \\
\hline \multicolumn{5}{|l|}{ Initial presentation } \\
\hline Clinical presentation & & & $>0.999$ & \\
\hline ST-segment elevation MI & $31(62.0)$ & $59(60.8)$ & & $74(69.8)$ \\
\hline Non-ST-segment elevation MI & $19(38.0)$ & $38(39.2)$ & & $32(30.2)$ \\
\hline Left ventricular ejection fraction (\%) & $30.0 \pm 11.1$ & $33.3 \pm 13.5$ & 0.189 & $37.4 \pm 15.4$ \\
\hline \multicolumn{5}{|l|}{ Laboratory findings } \\
\hline Hemoglobin (g/L) & $12.2 \pm 2.8$ & $12.1 \pm 2.2$ & 0.850 & $13.0 \pm 2.8$ \\
\hline Creatinine (mg/dL) & $1.7 \pm 1.3$ & $2.3 \pm 4.5$ & 0.248 & $1.7 \pm 1.6$ \\
\hline Prothrombin time (\%) & $78.5 \pm 19.7$ & $76.2 \pm 18.8$ & 0.531 & $79.1 \pm 24.8$ \\
\hline Lactic acid (mmol/L) & $5.6 \pm 4.9$ & $5.2 \pm 4.4$ & 0.706 & $8.5 \pm 4.8$ \\
\hline Troponin I (ng/mL), peak & $198.9 \pm 253.1$ & $191.6 \pm 214.1$ & 0.865 & $258.4 \pm 215.4$ \\
\hline CK-MB (ng/mL), peak & $213.3 \pm 277.9$ & $241.1 \pm 305.3$ & 0.614 & $385.6 \pm 365.5$ \\
\hline \multicolumn{5}{|l|}{ Previous scoring system } \\
\hline Glasgow Coma Score & $11.4 \pm 5.2$ & $12.7 \pm 4.3$ & 0.104 & $9.9 \pm 5.5$ \\
\hline ENCOURAGE Score & $16.9 \pm 8.0$ & $14.3 \pm 7.7$ & 0.054 & $18.4 \pm 7.6$ \\
\hline AMI-ECMO Score & $17.6 \pm 8.6$ & $16.4 \pm 9.3$ & 0.448 & $20.0 \pm 10.1$ \\
\hline
\end{tabular}

Data are presented as mean \pm standard deviation, or $n(\%)$. ${ }^{*} \mathrm{P}$ values indicated differences of variables between the ECMO before and after revascularization groups. AMI-ECMO, acute myocardial infarction-extracorporeal membrane oxygenation; CK-MB, creatine kinase-myocardial band; CVA, cerebrovascular accident; E-CPR, extracorporeal cardiopulmonary resuscitation; ENCOURAGE, prEdictioN of Cardiogenic shock OUtcome foR AMI patients salvaGed by VA-ECMO; MI, myocardial infarction; $\mathrm{PCI}$, percutaneous coronary intervention.

tors and thrombosuction were all left to the operators' preference. The final decision to insert VA-ECMO was determined by an experienced heart team, and the VAECMO was implanted at the bedside or in a catheterization laboratory by cardiovascular surgeons or interventional cardiologists. Detailed information of VA-ECMO management for AMI patients has been documented previously. ${ }^{15}$ Briefly, a percutaneous vascular approach was first tried using the Seldinger technique, but the surgical cutdown method was performed for those patients in whom percutaneous cannulation failed. The Capiox Emergency Bypass System (Capiox EBSTM; Terumo, Inc., Tokyo, Japan) and Permanent Life Support (PLS; MAQUET, Rastatt, Germany) were available in our hospital at the time of the study. Intravenous heparin was used to maintain an activated clotting time ranging from 150 to $180 \mathrm{~s}$ unless life-threatening bleeding developed. In the event of distal limb ischemia after arterial cannulation, a 7-French sheath was inserted distal to the cannulation site for limb perfusion. Pump speed was adjusted to obtain a cardiac index $>2.2 \mathrm{~L} / \mathrm{min} /$ body surface area $\left(\mathrm{m}^{2}\right)$, mean arterial pressure $>65 \mathrm{mmHg}$, and central mixed venous saturation $>70 \%$. Blood pressure was monitored continuously through an arterial catheter, and arterial blood gas analysis was measured in the artery of the right arm to estimate cerebral oxygenation. Successful weaning was defined as disconnection of the patient from ECMO without re-insertion or death within $24 \mathrm{~h}$. If myocardial damage was irre- 
Table 2. Baseline Angiographic Findings and In-Hospital Management

\begin{tabular}{|c|c|c|c|c|}
\hline \multirow[b]{2}{*}{ Variables } & \multicolumn{3}{|c|}{ Refractory cardiogenic shock } & \multirow{2}{*}{$\begin{array}{c}\text { Reference cohort } \\
\text { E-CPR before } \\
\text { revascularization } \\
(n=106)\end{array}$} \\
\hline & $\begin{array}{c}\text { Before } \\
\text { revascularization } \\
(n=50)\end{array}$ & $\begin{array}{c}\text { After } \\
\text { revascularization } \\
(n=97)\end{array}$ & P value* & \\
\hline \multicolumn{5}{|l|}{ Angiographic data } \\
\hline Culprit lesion location & & & 0.077 & \\
\hline Left main & $10(20.0)$ & $19(19.6)$ & & $31(29.2)$ \\
\hline Left anterior descending artery & $23(46.0)$ & $46(47.4)$ & & $48(45.3)$ \\
\hline Left circumflex artery & $3(6.0)$ & $18(18.6)$ & & $6(5.7)$ \\
\hline Right coronary artery & $14(28.0)$ & $14(14.4)$ & & $21(19.8)$ \\
\hline Anterior infarction & $33(66.0)$ & $65(67.0)$ & $>0.999$ & $79(74.5)$ \\
\hline Treatment strategy & & & 0.187 & \\
\hline $\mathrm{PCl}$ & $37(74.0)$ & $82(84.5)$ & & $94(88.7)$ \\
\hline Coronary artery bypass grafting & $13(26.0)$ & $15(15.5)$ & & $12(11.3)$ \\
\hline Successful revascularization & $49(98.0)$ & $89(91.8)$ & 0.257 & $102(96.2)$ \\
\hline MVD & $46(92.0)$ & $75(77.3)$ & 0.047 & $83(78.3)$ \\
\hline Complete revascularization (MVD only) & $29(63.0)$ & $41(54.7)$ & 0.474 & $42(50.6)$ \\
\hline Door to balloon time (min, STEMI only) & $105.0(72.0 \sim 123.5)$ & $79.5(65.0 \sim 120.0)$ & 0.260 & $114.5(81.0 \sim 138.0)$ \\
\hline Shock to ECMO time (min, STEMI only) & $83.0(33.0 \sim 158.0)$ & $90.0(25.0 \sim 417.5)$ & 0.967 & $40.0(23.5 \sim 60.5)$ \\
\hline Balloon to ECMO time (min) & $-20.5(-33.0 \sim-14.0)$ & $98.0(24.0 \sim 540.0)$ & $<0.001$ & $-49.0(-81.0 \sim-22.0)$ \\
\hline \multicolumn{5}{|l|}{ ECMO and other in-hospital management } \\
\hline E-CPR & $0(0)$ & $51(52.6)$ & $<0.001$ & $106(100)$ \\
\hline Undergoing CPR & $15(30.0)$ & $60(61.8)$ & $<0.001$ & $106(100)$ \\
\hline Pre-arrest rhythm & & & 0.005 & \\
\hline Ventricular tachycardia or fibrillation & $10(20.0)$ & $30(30.9)$ & & $48(45.3)$ \\
\hline Asystole & $1(2.0)$ & $6(6.2)$ & & $15(14.2)$ \\
\hline Pulseless electrical reactivity & $4(8.0)$ & $20(20.6)$ & & $35(33.0)$ \\
\hline Unknown & $0(0)$ & $4(4.1)$ & & $8(7.5)$ \\
\hline No CPR & $35(70.0)$ & $37(38.1)$ & & $0(0)$ \\
\hline CPR duration (min) & $16.0(10.0 \sim 26.0)$ & $13.0(5.0 \sim 30.0)$ & 0.685 & $25.0(14.0 \sim 37.0)$ \\
\hline ROSC before ECMO insertion & $15(100)$ & $23(38.3)$ & $<0.001$ & $36(34.0)$ \\
\hline Fluoroscopy guidance & $46(92.0)$ & $70(72.2)$ & 0.010 & $50(47.2)$ \\
\hline Successful ECMO insertion & $50(100)$ & $95(97.9)$ & 0.786 & $104(98.1)$ \\
\hline ECMO maintenance duration (days) & $4.0(2.0 \sim 6.0)$ & $4.0(3.0 \sim 6.0)$ & 0.640 & $4.0(2.0 \sim 6.0)$ \\
\hline Initial pump flow (L/min) & $3.2(2.4 \sim 3.8)$ & $3.2(2.7 \sim 3.7)$ & 0.531 & $3.5(3.0 \sim 4.0)$ \\
\hline Distal perfusion & $18(36.0)$ & $29(29.9)$ & 0.572 & $34(32.1)$ \\
\hline Continuous renal replacement therapy & $14(28.0)$ & $37(38.1)$ & 0.298 & $47(44.3)$ \\
\hline Mechanical ventilation & $38(76.0)$ & $85(87.6)$ & 0.116 & $98(92.5)$ \\
\hline Use of vasopressor/inotropes & $46(92.0)$ & $91(93.8)$ & 0.946 & $102(96.2)$ \\
\hline Norepinephrine & $26(52.0)$ & $59(60.8)$ & 0.395 & $80(75.5)$ \\
\hline Dopamine & $32(64.0)$ & $60(61.9)$ & 0.940 & $52(49.1)$ \\
\hline Dobutamine & $22(44.0)$ & $43(44.3)$ & $>0.999$ & $34(32.1)$ \\
\hline Epinephrine & $26(52.0)$ & $48(49.5)$ & 0.909 & $82(77.4)$ \\
\hline Vasopressin & $5(10.0)$ & $6(6.2)$ & 0.616 & $14(13.2)$ \\
\hline ICU stay (days, survived patients only) & $12.0(5.0 \sim 23.5)$ & $15.0(9.0 \sim 20.5)$ & 0.262 & $12.0(7.5 \sim 22.0)$ \\
\hline Hospital stay (days, survived patients only) & $12.0(3.5 \sim 56.5)$ & $17.5(8.0 \sim 42.0)$ & 0.524 & $16.0(7.0 \sim 32.0)$ \\
\hline
\end{tabular}

Data are presented as median (interquartile range), or $n(\%) .{ }^{*} \mathrm{P}$ values indicated differences of variables between the venoarterial-extracorporeal membrane oxygenation before and after revascularization groups. CPR, cardiopulmonary resuscitation; ICU, intensive care unit; MVD, multi-vessel disease; ROSC, return of spontaneous circulation; STEMI, ST-segment elevation myocardial infarction; other abbreviations are listed in Table 1.

versible and we could not wean the patient off the VA-ECMO, heart transplantation or LVAD implantation were considered.

\section{Data Collection and Outcomes}

The baseline demographic, hemodynamic, laboratory, and follow-up clinical outcome data were collected retrospec- tively through medical record review. When the same laboratory data were measured several times before ECMO insertion, the laboratory value measured at the nearest time to ECMO insertion was recorded. The ENCOURAGE (Prediction of cardiogenic shock outcome for AMI patients salvaged by VA-ECMO) and AMI-ECMO scores to predict clinical outcomes in AMI patients undergoing 
Table 3. In-Hospital Clinical Outcomes Between VA-ECMO Before and After Revascularization

\begin{tabular}{|c|c|c|c|c|c|c|c|c|c|}
\hline & \multicolumn{2}{|c|}{ Comparison cohort } & \multicolumn{3}{|c|}{ Univariate analysis } & \multicolumn{3}{|c|}{$\begin{array}{c}\text { Multivariable } \\
\text { analysis* }\end{array}$} & \multirow{2}{*}{$\begin{array}{c}\begin{array}{c}\text { Reference } \\
\text { cohort }\end{array} \\
\begin{array}{c}\text { E-CPR before } \\
\text { revascularization } \\
(n=106)\end{array}\end{array}$} \\
\hline & $\begin{array}{c}\text { Before } \\
\text { revascularization } \\
(n=50)\end{array}$ & $\begin{array}{c}\text { After } \\
\text { revascularization } \\
(n=97)\end{array}$ & OR & $\begin{array}{c}95 \% \\
\mathrm{Cl}\end{array}$ & $\begin{array}{c}\mathbf{P} \\
\text { value }\end{array}$ & OR & $\begin{array}{c}95 \% \\
\mathrm{Cl}\end{array}$ & $\begin{array}{c}P \\
\text { value }\end{array}$ & \\
\hline $\begin{array}{l}\text { A composite of in-hospital } \\
\text { mortality, LVAD } \\
\text { implantation, or heart } \\
\text { transplantation }\end{array}$ & $16(32.0)$ & $48(49.5)$ & 0.480 & $\begin{array}{l}0.235 \sim \\
0.982\end{array}$ & 0.045 & 0.360 & $\begin{array}{l}0.152 \sim \\
0.853\end{array}$ & 0.020 & $51(48.1)$ \\
\hline In-hospital mortality & $14(28.0)$ & $41(42.3)$ & 0.531 & $\begin{array}{c}0.254 \sim \\
1.110\end{array}$ & 0.093 & 0.373 & $\begin{array}{c}0.152 \sim \\
0.914\end{array}$ & 0.031 & $47(44.3)$ \\
\hline $\begin{array}{l}\text { In-hospital LVAD } \\
\text { implantation or heart } \\
\text { transplantation }\end{array}$ & $2(4.0)$ & $8(8.2)$ & 0.464 & $\begin{array}{l}0.100 \sim \\
2.270\end{array}$ & 0.343 & 0.376 & $\begin{array}{l}0.058 \sim \\
2.459\end{array}$ & 0.308 & $5(4.7)$ \\
\hline Limb ischemia & $2(4.0)$ & $8(8.2)$ & 0.464 & $\begin{array}{l}0.095 \sim \\
2.270\end{array}$ & 0.343 & 0.450 & $\begin{array}{c}0.063 \sim \\
3.214\end{array}$ & 0.426 & $13(12.3)$ \\
\hline Cerebrovascular accidents & $2(4.0)$ & $13(13.4)$ & 0.269 & $\begin{array}{c}0.058 \sim \\
1.244\end{array}$ & 0.093 & 0.267 & $\begin{array}{c}0.049 \sim \\
1.448\end{array}$ & 0.126 & $13(12.3)$ \\
\hline Major bleeding events ${ }^{\dagger}$ & $7(14.0)$ & $17(17.5)$ & 0.766 & $\begin{array}{c}0.295 \sim \\
1.991\end{array}$ & 0.584 & 0.965 & $\begin{array}{c}0.310 \sim \\
3.003\end{array}$ & 0.951 & $21(19.8)$ \\
\hline
\end{tabular}

Values are presented as $\mathrm{n}(\%)$. *Adjusted variables included age, sex, diabetes mellitus, current smoker, previous history of myocardial infarction, ST-segment elevation myocardial infarction, left ventricular ejection fraction, ENCOURAGE score, culprit lesion location, multi-vessel disease, fluoroscopy guidance, and mechanical ventilation. 'Major bleeding was defined as Bleeding Academic Research Consortium type 3-5. Cl, confidence interval; E-CPR, extracorporeal cardiopulmonary resuscitation; LVAD, left ventricular assist device; OR, odds ratio; VA-ECMO, venoarterial-extracorporeal membrane oxygenation.

VA-ECMO were calculated. ${ }^{16,17}$ Additional clinical information was obtained from medical records and telephone interviews if necessary.

The primary outcome was a composite of in-hospital mortality, LVAD implantation, and heart transplantation. The secondary outcomes included in-hospital mortality, LVAD implantation or heart transplantation, VA-ECMOrelated complications such as limb ischemia, cerebrovascular accidents, and major bleeding (Bleeding Academic Research Consortium type 3 to 5). ${ }^{\mathbf{1 8}}$ To explore the consistency of the clinical outcomes during follow up, a composite of mortality, LVAD implantation, and heart transplantation was also analyzed at 1-year after the index procedure.

\section{Statistical Analysis}

Categorical variables were tested using the Chi-squared test or Fisher's exact test, as appropriate, and presented as numbers and relative frequencies. Continuous variables were compared the using the Welch's t-test or the Wilcoxon rank sum test, as appropriate, and presented as mean \pm standard deviation or median $\left(25^{\text {th }}\right.$ to $75^{\text {th }}$ percentile). The risks of primary and secondary outcomes were compared using logistic regression analysis and were presented as odds ratios (OR) and 95\% confidence intervals (CI). In the multivariable models, we included the covariates that were significant in univariate analysis or those that were clinically relevant. The adjusted ORs and 95\% CIs were acquired by using a multivariable logistic regression model based on age, sex, diabetes mellitus, current smoker, previous history of MI, ST-segment elevation MI, left ventricular ejection fraction, ENCOURAGE score, culprit lesion location, multi-vessel disease, fluoroscopy guidance, and mechanical ventilation. The cumulative incidence of clinical events was evaluated by Kaplan-Meier analyses and the level of significance was assessed by using the log-rank test. Cox proportional hazards regression analysis was also performed to compare the risk of clinical events at 1-year follow up. Statistical analyses were per- formed using R Statistical Software (version 3.5.2; R Foundation for Statistical Computing, Vienna, Austria) with $\mathrm{P}<0.05$ considered statistically significant.

\section{Results}

\section{Baseline Clinical Characteristics}

Within the study population, VA-ECMO was used in 106 patients $(41.9 \%)$ during CPR for cardiac arrest before revascularization (reference cohort). In the remaining 147 patients, who presented with AMI and refractory CS, VAECMO was used before $(n=50,34.0 \%)$ and after $(n=97$, $66.0 \%$ ) coronary artery revascularization (comparison cohort). Supplementary Table 1 presents the baseline clinical and laboratory characteristics between comparison and reference cohorts. Compared with the reference cohort, the comparison cohort had significantly lower left ventricular ejection fraction, hemoglobin, lactic acid, cardiac enzyme, ENCOURAGE, and AMI-ECMO scores, but a higher Glasgow Coma Score. In the comparison cohort, the VAECMO before revascularization group was slightly older, more likely to have diabetes mellitus, a lower left ventricular ejection fraction and Glasgow Coma Score, and higher ENCOURAGE and AMI-ECMO scores compared with the VA-ECMO after revascularization group, but all baseline clinical variables were not statistically significant (Table 1).

\section{Angiographic Findings and Management}

Baseline angiographic findings and in-hospital management between comparison and reference cohort are shown in Supplementary Table 2, and those between VA-ECMO before and after revascularization are shown in Table 2. Among patients with ST-segment elevation MI, the comparison cohort showed significantly shorter D2B time, but a longer shock-to-ECMO time than the reference cohort (Supplementary Table 2). The proportion of patients undergoing PCI and complete revascularization for multi- 
A. All-cause Death, LVAD Implantation or Heart Transplantation

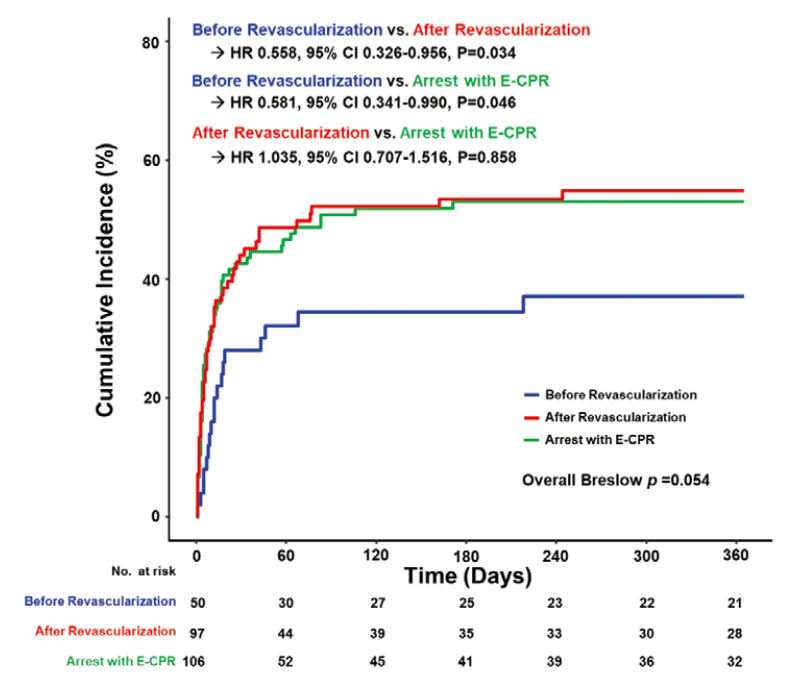

\section{B. All-cause Death}

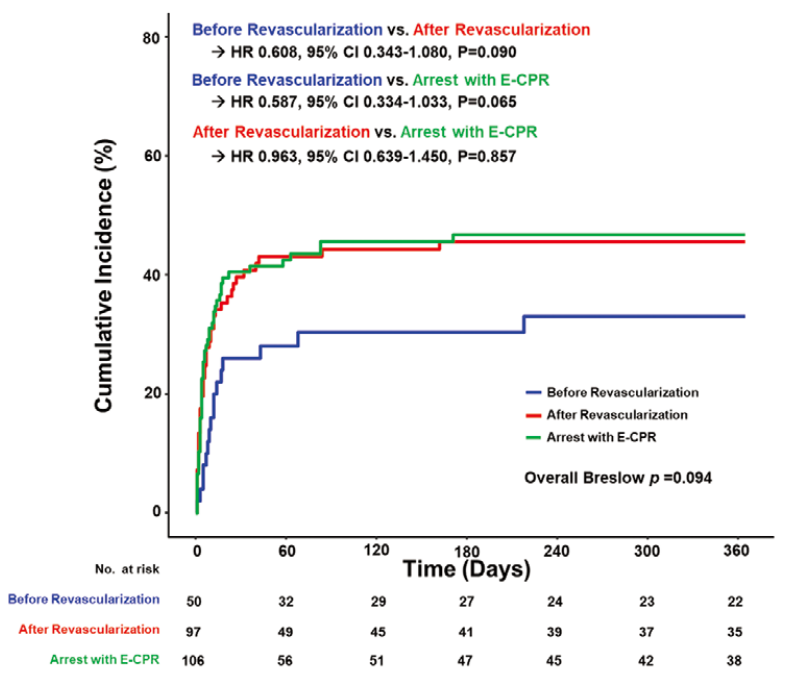

C. LVAD Implantation or Heart Transplantation

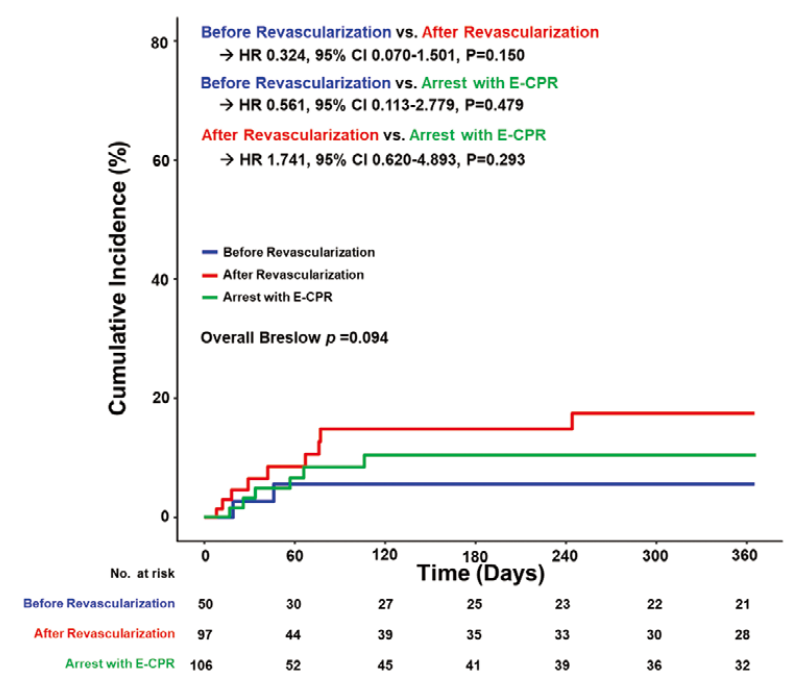

Figure 2. Comparison of 1-year clinical outcomes according to the timing of the VA-ECMO insertion. Kaplan-Meier curves to compare $(\mathbf{A})$ all-cause death, LVAD implantation, or heart transplantation; (B) all-cause death; and (C) LVAD implantation or heart transplantation in patients with acute myocardial infarction complicated by cardiogenic shock according to the timing of the VAECMO insertion. E-CPR, extracorporeal cardiopulmonary resuscitation; LVAD, left ventricular assist device; VA-ECMO, venoarterial-extracorporeal membrane oxygenation.

vessel disease did not differ between the 2 groups. Among the comparison cohort, D2B time was slightly longer, but shock-to-ECMO time was slightly shorter in patients with ST-segment elevation MI who underwent VA-ECMO before revascularization than in those with VA-ECMO after revascularization, without statistically significant differences (Table 2). There were significantly higher percentages of multi-vessel disease in the VA-ECMO before revascularization group, but complete revascularization rate was not significantly different between the 2 groups.

Unlike the reference cohort in which all patients underwent VA-ECMO during CPR, the rates of E-CPR in the comparison cohort was $34.7 \%$ (Supplementary Table 2). The comparison cohort also showed a significantly shorter duration of CPR, a higher proportion of return of spontaneous circulation before ECMO insertion, and higher rates of fluoroscopy-guided VA-ECMO insertion, compared with the reference cohort. In the comparison cohort, VAECMO insertion was not performed during CPR in the VA-ECMO before revascularization group, but $52.6 \%$ of patients received E-CPR in the VA-ECMO after revascularization group (Table 2). In addition, fluoroscopy guidance was more frequently performed in the VA-ECMO before revascularization group.

\section{Clinical Outcomes}

A composite of in-hospital mortality, LVAD implantation, and heart transplantation occurred in 60 patients $(40.8 \%)$ 
from the comparison cohort and 51 patients (48.1\%) from the reference cohort. Among the comparison cohort, the primary outcome was significantly lower in the VA-ECMO before revascularization group than in the VA-ECMO after revascularization group (before vs. after, $32.0 \%$ vs. $49.5 \%$, OR $0.480,95 \%$ CI $0.235-0.982, \mathrm{P}=0.045$ ) (Table 3). There was little difference in the incidence of a primary outcome between patients who had VA-ECMO after revascularization and patients in the reference cohort (after vs. reference, $49.5 \%$ vs. $48.1 \%$, OR 1.056 , 95\% CI, 0.609 $1.833, \mathrm{P}=0.845$ ), but there was a large difference between patients who had VA-ECMO before revascularization and patients in the reference cohort (before vs. reference, $32.0 \%$ vs. $48.1 \%$, OR $0.488,95 \%$ CI $0.236-1.010, \mathrm{P}=0.053$ ). Although the VA-ECMO before revascularization group had numerically lower rates of in-hospital VA-ECMOrelated complications, including limb ischemia, cerebrovascular accidents, and major bleeding events, there were no statistically significant differences among the 3 groups (Table 3).

Clinical outcomes at 1-year follow up showed consistent results with primary and secondary outcomes (Figure 2). Patients who underwent VA-ECMO before revascularization were associated with a significantly lower risk of allcause death, LVAD implantation, and heart transplantation at 1 year after the index procedure compared to those with VA-ECMO after revascularization (before vs. after, 37.1\% vs. $54.9 \%$, hazard ratio $0.558,95 \%$ CI $0.326-0.956, \mathrm{P}=0.034$ ) or those who had a cardiac arrest with E-CPR (before vs. reference, $37.1 \%$ vs. $53.0 \%$, hazard ratio $0.581,95 \% \mathrm{CI}$ $0.341-0.990, \mathrm{P}=0.046)$. Other independent predictors of a composite of all-cause death, LVAD implantation, and heart transplantation at 1 year included male, LVEF, and ENCOURAGE score (Supplementary Table 3).

\section{Discussion}

In the present study, we found that early initiation of VAECMO before revascularization therapy was associated with a significantly lower risk of composite in-hospital mortality, LVAD implantation, and heart transplantation, compared with VA-ECMO insertion after revascularization in patients with AMI complicated by refractory CS without E-CPR before revascularization. The difference in outcome between the 2 strategies was mainly driven by the rate of in-hospital mortality. In particular, these findings were consistent at the 1-year follow up.

\section{Application of VA-ECMO in Patients With AMI and Refractory CS}

In the setting of AMI with CS refractory to conventional medical therapy, VA-ECMO can provide temporary mechanical full hemodynamic cardiopulmonary support until recovery of cardiac function. ${ }^{19-22}$ However, VAECMO has inherent device-related complications and the overuse of VA-ECMO might be associated with raised hospital costs and an unnecessary extension of therapy without the benefit of sufficient mortality. ${ }^{23}$ Furthermore, there was a lack of strong evidence on the benefits of VAECMO in patients with AMI and refractory CS. Therefore, initiation and maintenance of VA-ECMO should be carefully considered by experienced experts using a tradeoff between risk and benefit. In AMI patients who have a cardiac arrest before revascularization treatment (e.g., outof-hospital cardiac arrest, or in-hospital cardiac arrest in the emergency department), VA-ECMO insertion with $\mathrm{E}-\mathrm{CPR}$ is inevitably used to rescue patients. In contrast, in patients who arrive at the catheterization laboratory with AMI complicated by refractory CS without cardiac arrest, it is very difficult to decide whether to use revascularization therapy first or VA-ECMO insertion. The main concerns of using VA-ECMO as a first strategy are that it might delay D2B time and increase oxygen demand for the infarcted myocardium by increased afterload.

\section{Benefits of the Early Initiation of VA-ECMO}

Although several observational studies have shown that the VA-ECMO assisted primary PCI strategy is feasible and has acceptable outcomes, there have been limited data regarding the optimal timing of VA-ECMO initiation in AMI patients with refractory CS. ${ }^{7-11}$ Huang et al recently reported ECMO before PCI improves both short- and long-term outcomes, when compared with ECMO after PCI. ${ }^{24}$ Nevertheless, the previous study had several limitations in applying the real-world practice to AMI patients with refractory CS. First, the overall number of the analyzed population was only 46 patients (12 ECMO before PCI and 34 ECMO after PCI). Second, all of the patients in the ECMO before PCI group underwent CPR, and $41.7 \%$ of the patients have received VA-ECMO implantation during CPR. In other words, the benefit of the pre-emptive application of VA-ECMO prior to PCI could not be determined because the insertion of VA-ECMO under cardiac arrest is an inevitable situation that does not depend on the operator's discretion. Therefore, we conducted the current study to identify the prognostic effect of the early initiation of VA-ECMO among patients with AMI complicated by refractory CS who did not undergo E-CPR before revascularization. In agreement with the previous study, we found that VA-ECMO insertion before revascularization was significantly associated with better clinical outcomes in patients with AMI and refractory CS without undergoing E-CPR before revascularization, despite a slight delay of D2B time in the STEMI subsets. Furthermore, the VAECMO before revascularization group had numerically lower risks of ECMO-related complications, including limb ischemia, cerebrovascular accidents, or major bleeding, and surviving patients had shorter hospital days compared with the VA-ECMO after revascularization group. The differences between the 2 strategies seem to occur because the VA-ECMO was inserted more stably with fluoroscopy guidance before revascularization. Indeed, in $52.6 \%$ of the patients who underwent VA-ECMO after revascularization, the VA-ECMO was inserted during CPR, but in all of the patients who underwent VA-ECMO before revascularization, the VA-ECMO was inserted without CPR. One of the other potential explanations for the benefit of early VA-ECMO is in the prevention of multi-organ damage by sudden cardiac arrest due to reperfusion injury, unexpected arrhythmia, or procedure-related complications such as no-reflow, coronary dissection, and perforation, during revascularization treatment. Taken together, the early initiation of VA-ECMO might improve clinical outcomes, even in patients with AMI complicated by refractory CS without cardiac arrest before revascularization. A large, well-designed, randomized controlled trial for comparison between active and conservative MCS strategies in AMI patients with refractory CS would be warranted to confirm our findings. 


\section{Comparison With Axial-Flow Intracorporeal Pump}

Physiologically, the afterload from retrograde VA-ECMO flow may contribute to the over-distension and ischemic damage of the left ventricle. In this regard, axial-flow with an intracorporeal pump such as Impella (AbioMed, Danvers, MA, USA), which provides unloading of the left ventricle, has been developed and used for patients with AMI and CS. However, unlike VA-ECMO, Impella cannot provide unloading of the right ventricle, or gas exchange with pulmonary support; therefore, Impella devices should be upgraded to VA-ECMO in the setting of cardiac arrest, hypoxemia, and progressive biventricular failure. Similar to the VA-ECMO data, several observational studies have demonstrated that implantation of Impella prior to PCI was associated with a significantly lower in-hospital mortality compared with post-PCI Impella implantation. ${ }^{25-27}$ Therefore, previous and current studies suggest that preemptive application of MCS might be considered as a therapeutic option for AMI patients with profound CS.

\section{Study Limitations}

The present study has several limitations. First, because the study population originated from the institutional VAECMO registry, no comparison with patients with AMI complicated by CS without VA-ECMO was performed. Second, the non-randomized nature of registry data could have resulted in selection bias, and the selection of treatment strategy might reflect the preference of individual physicians. Third, although, to our knowledge, this was the largest sized study for comparing VA-ECMO before and after revascularization, sample sizes were probably inadequate for the analysis of ECMO-related complications between the 2 groups. Fourth, we cannot compare VA-ECMO with new MCS devices, such as Impella, because they are not currently available in Korea. Finally, clinical outcomes might be affected by time-dependent variables such as advanced devices and techniques because enrolment occurred over 14 years in this registry. Despite these limitations, due to the difficulty in constructing a randomized controlled trial for patients presenting with shock, the current study provides a valuable insight into the benefits of the early initiation of VA-ECMO in patients with AMI complicated by refractory CS.

\section{Conclusions}

Among patients with AMI complicated by refractory CS who did not undergo E-CPR before revascularization, VAECMO insertion before revascularization showed a significantly lower risk of composite in-hospital mortality, LVAD implantation, and heart transplantation compared with VA-ECMO insertion after revascularization. The early initiation of MCS should be actively considered in AMI patients with refractory CS to improve clinical outcomes.

\section{Disclosures}

The authors have no conflicts of interest to declare.

\section{References}

1. Jeger RV, Radovanovic D, Hunziker PR, Pfisterer ME, Stauffer $\mathrm{JC}$, Erne P, et al. Ten-year trends in the incidence and treatment of cardiogenic shock. Ann Intern Med 2008; 149: 618-626.

2. Goldberg RJ, Spencer FA, Gore JM, Lessard D, Yarzebski J. Thirty-year trends (1975 to 2005) in the magnitude of, manage- ment of, and hospital death rates associated with cardiogenic shock in patients with acute myocardial infarction: A population-based perspective. Circulation 2009; 119: 1211-1219.

3. Wayangankar SA, Bangalore S, McCoy LA, Jneid H, Latif F, Karrowni W, et al. Temporal trends and outcomes of patients undergoing percutaneous coronary interventions for cardiogenic shock in the setting of acute myocardial infarction: A report from the CathPCI Registry. JACC Cardiovasc Interv 2016; 9: $341-351$.

4. Rihal CS, Naidu SS, Givertz MM, Szeto WY, Burke JA, Kapur NK, et al. 2015 SCAI/ACC/HFSA/STS clinical expert consensus statement on the use of percutaneous mechanical circulatory support devices in cardiovascular care: Endorsed by the American Heart Assocation, the Cardiological Society of India, and Sociedad Latino Americana de Cardiologia Intervencion; Affirmation of Value by the Canadian Association of Interventional CardiologyAssociation Canadienne de Cardiologie d'intervention. $J$ Am Coll Cardiol 2015; 65: e7-e26.

5. Werdan K, Gielen S, Ebelt H, Hochman JS. Mechanical circulatory support in cardiogenic shock. Eur Heart J 2014; 35: $156-167$.

6. Thiele H, Smalling RW, Schuler GC. Percutaneous left ventricular assist devices in acute myocardial infarction complicated by cardiogenic shock. Eur Heart J 2007; 28: 2057-2063.

7. Sheu JJ, Tsai TH, Lee FY, Fang HY, Sun CK, Leu S, et al. Early extracorporeal membrane oxygenator-assisted primary percutaneous coronary intervention improved 30-day clinical outcomes in patients with ST-segment elevation myocardial infarction complicated with profound cardiogenic shock. Crit Care Med 2010; 38: 1810-1817.

8. Kim H, Lim SH, Hong J, Hong YS, Lee CJ, Jung JH, et al. Efficacy of veno-arterial extracorporeal membrane oxygenation in acute myocardial infarction with cardiogenic shock. Resuscitation 2012; 83: $971-975$.

9. Sakamoto S, Taniguchi N, Nakajima S, Takahashi A. Extracorporeal life support for cardiogenic shock or cardiac arrest due to acute coronary syndrome. Ann Thorac Surg 2012; 94: 1-7.

10. Chung SY, Tong MS, Sheu JJ, Lee FY, Sung PH, Chen CJ, et al. Short-term and long-term prognostic outcomes of patients with ST-segment elevation myocardial infarction complicated by profound cardiogenic shock undergoing early extracorporeal membrane oxygenator-assisted primary percutaneous coronary intervention. Int J Cardiol 2016; 223: 412-417.

11. Chung ES, Lim C, Lee HY, Choi JH, Lee JS, Park KH. Results of extracorporeal membrane oxygenation (ECMO) support before coronary reperfusion in cardiogenic shock with acute myocardial infarction. Korean J Thorac Cardiovasc Surg 2011; 44: $273-278$.

12. O'Gara PT, Kushner FG, Ascheim DD, Casey DE Jr, Chung MK, de Lemos JA, et al. 2013 ACCF/AHA guideline for the management of ST-elevation myocardial infarction: A report of the American College of Cardiology Foundation/American Heart Association Task Force on Practice Guidelines. J Am Coll Cardiol 2013; 61: e78-e140.

13. Neumann FJ, Sousa-Uva M, Ahlsson A, Alfonso F, Banning AP, Benedetto U, et al. 2018 ESC/EACTS guidelines on myocardial revascularization. Eur Heart J 2019; 40: 87-165.

14. Ibanez B, James S, Agewall S, Antunes MJ, Bucciarelli-Ducci C, Bueno H, et al. 2017 ESC guidelines for the management of acute myocardial infarction in patients presenting with ST-segment elevation: The Task Force for the management of acute myocardial infarction in patients presenting with ST-segment elevation of the European Society of Cardiology (ESC). Eur Heart J 2018; 39: $119-177$.

15. Park TK, Yang JH, Choi SH, Song YB, Hahn JY, Choi JH, et al. Clinical impact of intra-aortic balloon pump during extracorporeal life support in patients with acute myocardial infarction complicated by cardiogenic shock. BMC Anesthesiol 2014; 14: 27.

16. Muller G, Flecher E, Lebreton G, Luyt CE, Trouillet JL, Brechot $\mathrm{N}$, et al. The ENCOURAGE mortality risk score and analysis of long-term outcomes after VA-ECMO for acute myocardial infarction with cardiogenic shock. Intensive Care Med 2016; 42: $370-378$.

17. Choi KH, Yang JH, Park TK, Lee JM, Song YB, Hahn JY, et al. Risk prediction model of in-hospital mortality in patients with myocardial infarction treated with venoarterial extracorporeal membrane oxygenation. Rev Esp Cardiol (Engl Ed) 2018; 72: $724-731$.

18. Mehran R, Rao SV, Bhatt DL, Gibson CM, Caixeta A, Eikelboom 
J, et al. Standardized bleeding definitions for cardiovascular clinical trials: A consensus report from the Bleeding Academic Research Consortium. Circulation 2011; 123: 2736-2747.

19. Abrams D, Combes A, Brodie D. Extracorporeal membrane oxygenation in cardiopulmonary disease in adults. $\mathrm{J} \mathrm{Am}$ Coll Cardiol 2014; 63: $2769-2778$.

20. Stretch R, Sauer CM, Yuh DD, Bonde P. National trends in the utilization of short-term mechanical circulatory support: Incidence, outcomes, and cost analysis. J Am Coll Cardiol 2014; 64: $1407-1415$.

21. Combes A, Leprince P, Luyt CE, Bonnet N, Trouillet JL, Leger $\mathrm{P}$, et al. Outcomes and long-term quality-of-life of patients supported by extracorporeal membrane oxygenation for refractory cardiogenic shock. Crit Care Med 2008; 36: 1404-1411.

22. Kar B, Gregoric ID, Basra SS, Idelchik GM, Loyalka P. The percutaneous ventricular assist device in severe refractory cardiogenic shock. J Am Coll Cardiol 2011; 57: 688-696.

23. Cheng R, Hachamovitch R, Kittleson M, Patel J, Arabia F, Moriguchi J, et al. Complications of extracorporeal membrane oxygenation for treatment of cardiogenic shock and cardiac arrest: A meta-analysis of 1,866 adult patients. Ann Thorac Surg 2014; 97: 610-616.

24. Huang CC, Hsu JC, Wu YW, Ke SR, Huang JH, Chiu KM, et al. Implementation of extracorporeal membrane oxygenation before primary percutaneous coronary intervention may improve the survival of patients with ST-segment elevation myocardial infarction and refractory cardiogenic shock. Int J Cardiol 2018; 269: $45-50$.

25. Loehn T, O’Neill WW, Lange B, Pfluecke C, Schweigler T, Mierke J, et al. Long term survival after early unloading with Impella $\mathrm{CP}(\mathrm{R}))$ in acute myocardial infarction complicated by cardiogenic shock. Eur Heart J Acute Cardiovasc Care 2020; 9: $149-157$.

26. Basir MB, Schreiber TL, Grines CL, Dixon SR, Moses JW, Maini BS, et al. Effect of early initiation of mechanical circulatory support on survival in cardiogenic shock. Am J Cardiol 2017; 119: 845-851.

27. Schroeter MR, Kohler H, Wachter A, Bleckmann A, Hasenfuss $\mathrm{G}$, Schillinger W. Use of the impella device for acute coronary syndrome complicated by cardiogenic shock: Experience from a single heart center with analysis of long-term mortality. J Invasive Cardiol 2016; 28: 467-472.

\section{Supplementary Files}

Please find supplementary file(s);

http://dx.doi.org/10.1253/circj.CJ-20-0259 